\title{
USE OF VARIOUS BAITS FOR EXTRACTION OF EARTHWORMS FROM VERMICOMPOST
}

\author{
Joanna Kostecka', Vinod Kumar Garg ${ }^{2}$ \\ 1 Department of Biological Basis of Agriculture and Environmental Education, Faculty of Biology and \\ Agriculture, University of Rzeszow, Ćwiklińskiej 1, 35-601 Rzeszów, Poland, e-mail: jkosteck@ur.edu.pl \\ 2 Department of Environmental Science and Engineering, Guru Jambheshwar University of Science and \\ Technology, Hisar, 125001 Haryana, India, e-mail: vinodkgarg@yahoo.com
}

Received: 2015.09 .16

Accepted: 2015.10 .06

Published: 2015.11.10

\begin{abstract}
During vermicomposting, earthworm grower has to overcome a lot of different problems. For instance, in case of a sudden requirement to sell earthworms it is useful to have the ability to collect them in one place. Fresh food extraction is an effective and neutral way to do it. The efficiency of gathering and extracting E. fetida from the vermicompost was studied, using a fresh bait method. Experiments were carried out in the laboratory (at the mean temperature of $20 \pm 0.5^{\circ} \mathrm{C}$ ) in pots filled with vermicompost. Generally, two hundreds of adult $E$. fetida were put in every pot and left there for 24 hours. After such acclimatization, various baits were inserted to every pot. Different experiments allowed to conclude that: 1) repeated bait exchange was more efficient in extracting worms from vermicompost than bait laid once for a longer time; 2) extracting worms from the bait in the morning was quicker than extracting them in the evening; 3) addition of valerian (Valeriana officinalis), nettle (Urtica dioica), and flaxseeds to cattle manure could resulted in better extraction than pure manure; 4) dry valerian was more effective than steamed one, but on other hand, steaming of nettle and flaxseeds was giving better results in collecting worms in the bait.
\end{abstract}

Keywords: earthworm, vermicomposting, fresh food extraction, E. fetida.

\section{INTRODUCTION}

Breeding earthworms on organic waste can take place on small, medium and large scale. Its course depends on many external factors (abiotic and biotic) and the internal characteristics of species [Kostecka 2009, Kostecka et al. 2011]. The Department of Biological Foundations of Agriculture and Environmental Education, University of Rzeszow has conducted research on vermicomposting for many years [Kostecka and Błażej 2000, Kostecka and Pączka 2006, Kostecka and Garczyńska 2012, Pączka and Kostecka 2012]. Similarly extensive research on vermicomposting of organic waste are conducted at the Department of Environmental Science and Engineering, Guru Jambheshwar University of Science and Technology in India [Kaushik and Garg 2003, Gupta and Garg 2011, Garg et al. 2012, Gupta et al. 2014].
Speaking of breeding earthworms, also the economic aspect must be stressed which implies the issue of the need for rapid extraction of earthworms from the vermiculture substrate. The method of earthworm extraction from vermicompost produced by them is one of the problems in vermiculture business running, as for instance when it is necessary to rarefy excessively dense population, or when a grower has a sudden requirement to sell earthworms. Therefore, it is useful to have the ability to collect them in one place. When considering the extraction of earthworms from vermicompost that action should be modeled "in a sense" on the research of quality and quantity of earthworms in the soil. And then it is a question of their mining on the surface of the soil environment.

Earthworm numbers in soil samples may be assessed in various methods: direct (physical), 
indirect (ethological) or combined [Edwards and Bohlen 1996]. The extraction method employing fresh food bait, used in practice by earthworm growers is effective [Gaddie and Douglas 1977], although it is still tested and optimalized. As stated by Bouche and Gardner [1984], unknown inventors developed it in 1930-1935. It consists in offering hungry worms fresh organic substance at which they shall eagerly gather. A thin layer of fresh food with worms may then be easily extracted and moved to new culture or sorted manually to select individuals suitable for the purpose. Fresh food extraction is effective and neutral way to do it.

Research was conducted with the aim for applying various baits for effective extraction of $E$. fetida compost worm from vermicompost.

\section{MATERIAL AND METHODS}

\section{Comparison of methods: multiple bait change and single bait laying}

The research was conducted in the laboratory at $20 \pm 0.5{ }^{\circ} \mathrm{C}$. The individuals, collected from own vermiculture system run on cattle manure, were kept in the laboratory for 24 hours, and then adult individuals were chosen for the experiment.

Four pots of 60 liter capacity were filled with vermicompost (moisture of $70 \%$ ) and then two hundreds of $E$. fetida individuals were introduced into each. By the evening, after earthworm acclimatization, baits of fresh cattle manure ( $\mathrm{pH} 7.5)$ were put into all pots in a form of $1-\mathrm{dm}^{3}$ prone, laid centrally on the surface of each pot. The bait was checked after 12 hours in pot I, after 24 hours in pot II, after 36 hours in pot III, while the worms which gathered in it, were extracted by manually sorting and counted. Individuals found in the bait were removed from the experiment but the new bait was put in the pots. This operation was repeated until $100 \%$ of previously introduced worms were extracted. In pot IV (continuous test) the bait was left undisturbed until the moment when $100 \%$ individuals were collected in one of the remaining three pots. Then the bait in pot IV was checked also with all the extracted individuals being counted.

The experiment was conducted in 5 replications. The obtained data were subjected to a statistical analysis. The evaluated parameters were the differences between average times for extracting $100 \%$ of individuals out of vermicompost for frequencies of bait exchange of 12, 24 and 36 hours. The differences in the effectiveness of multiple bait change were also evaluated versus single bait laying.

\section{Comparison of extraction effectiveness at various times of the day}

The experiment was conducted in 4 consecutive replications. The effectiveness of food bait extraction was compared for various times of day (morning and evening).

Two hundreds E. fetida individuals were introduced to each of 2 pots filled with vermicompost and left to acclimatize. Then the cattle manure baits were put into each pot but at different times, i.e. at 8 p.m. in pot I and at 8 a.m. in pot II. The frequency of bait replacement was the same in both pots -24 hours, but consecutive bait changes were always at $8 \mathrm{p} . \mathrm{m}$. in pot I and at 8 a.m. in pot II. This operation was repeated until the moment all individuals were extracted.

\section{Determination of extraction effectiveness with the use of bait from cattle manure mixed with various additives}

The experiments were carried out also in the laboratory (at similar conditions) in twenty liter pots filled by vermicompost. Generally, one hundred of matured E. fetida individuals were put in every pot and left there for 24 hours, then various baits were tested.

Two $1-\mathrm{dm}^{3}$ probes of bait were introduced in each pot: one of cattle manure and one of the same manure but mixed with valerian (Valeriana officinalis), nettle (Urtica dioica), or flaxseed (Table 1). The time of earthworm extraction from vermicompost was determined by multiple check of E. fetida in the baits. The experiment was repeated 3 times. Data obtained in experiments were subjected to analysis using t-Student $(\mathrm{p}=0.05)$ test.

\section{RESULTS}

\section{Comparison of methods: multiple bait change and single bait laying}

The research confirmed the effectiveness of bait extraction method. It showed a statistically significant relation between the average extraction time (of all E. fetida individuals previously introduced in vermicompost), and the method of 
Table 1. Method of preparing test mixtures for earthworm extraction from vermicompost

\begin{tabular}{|l|c|c|c|c|c|}
\hline \multicolumn{1}{|c|}{ Pot } & I & II & III & IV & V \\
\hline Bait type & \multicolumn{5}{|c|}{ cattle manure + valerian } \\
\hline Valerian: manure & $1^{\mathrm{A}}: 20$ & $1^{\mathrm{B}}: 20$ & $1^{\mathrm{A}}: 10$ & $1^{\mathrm{B}}: 10$ & $1^{\mathrm{A}}: 5$ \\
\hline Bait type & \multicolumn{7}{|c|}{ cattle manure + nettle } \\
\hline Nettle: manure & $1: 5$ & $1: 3$ & $1: 1$ & $2: 3$ & $4: 3$ \\
\hline Bait type & \multicolumn{7}{|c|}{ cattle manure + flax seed } \\
\hline Flaxseed: manure & $1: 3$ & $2: 3$ & $1: 1$ & $4: 3$ & $1: 0$ \\
\hline
\end{tabular}

A - in dry, powdered condition, B - steamed

bait inspection. Earthworms were extracted significantly more rapidly when bait was inspected and changed every 12 or 36 hours, compared to bait changed every 24 hours (Table 2). However, in practice it meant different labor input (with bait inspection every 36 hours only 6 bait changes were necessary, whereas, when inspecting every 12 hours, $100 \%$ of individuals were extracted only after approx. 17 bait changes).

It was also shown that the effectiveness of multiple putting of bait was significantly higher $(p=0.05)$ compared to single (even longer) bait laying. At the time, when complete extraction (of $100 \%$ of individuals) was accomplished in the first pot, only $49 \pm 7 \%$ introduced individuals were found on bait in pot IV with continued, one bait.

Table 2. Time [hour] needed for extraction $100 \%$ of population from vermicompost as dependent on period of the bait changing

\begin{tabular}{|l|c|c|c|}
\hline \multirow{2}{*}{$\begin{array}{l}\text { Time needed for } \\
\text { extraction of all intro- } \\
\text { duced individuals [h] }\end{array}$} & $216 \pm 12$ & $232 \pm 24$ & $216 \pm 0$ \\
\cline { 2 - 4 } & 12 hours & 24 hours & 36 hours \\
\cline { 2 - 4 } & & & \\
\hline
\end{tabular}

\section{Comparison of extraction effectivenes at various times of the day}

All the experiment replications showed consistently that $100 \%$ of individuals were extracted from vermicompost significantly more rapidly when the bait checking was performed in the morning (Figure 1).

In case of morning extraction of earthworms, all of them were removed from vermicompost after an average of $7.3 \pm 0.6$ bait exchanges while, in case of evening inspection and bait exchange, all were recaptured only after $10.3 \pm 1.2$ exchanges.

\section{Determining of worm extraction effectiveness with the use of manure bait with various additions}

The analysis of the attractiveness of manure bait mixed with valerian in reference to pure manure (Table 3). showed that use of too large quantities of valerian reduced the effectiveness of baiting mixture. Significantly more effective than manure was only the trap containing $1 / 20$ part of dry powdered valerian.

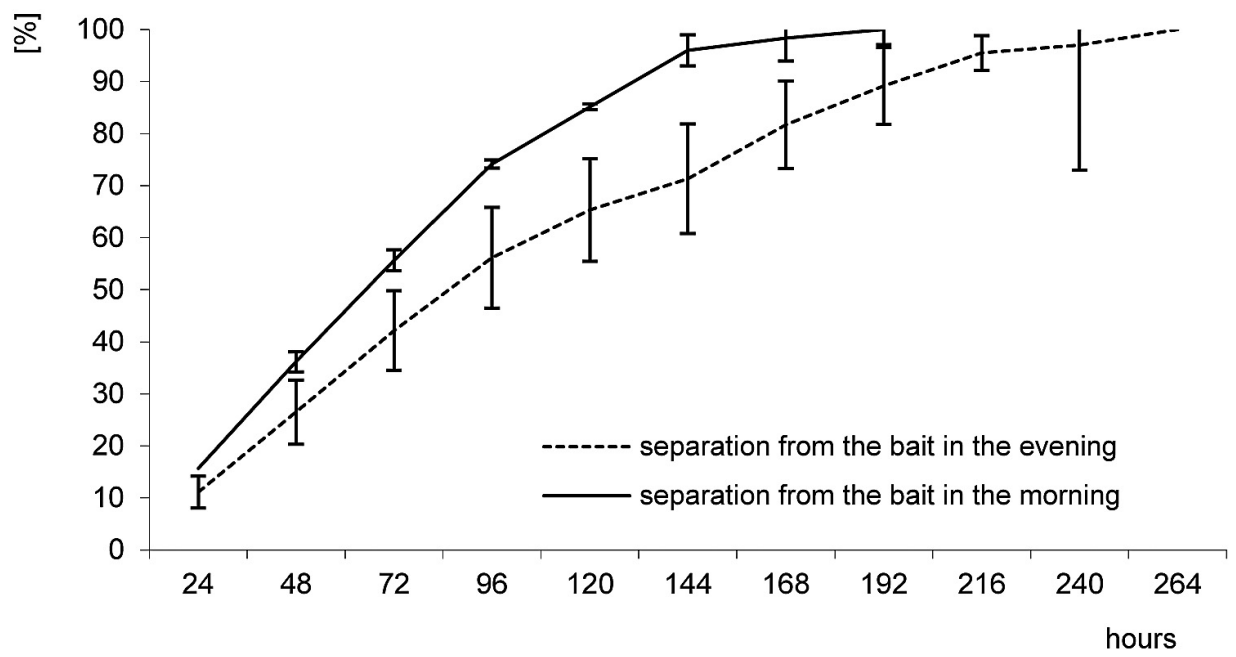

Figure 1. Effectiveness [\%] of checking the bait in the morning or in the evening 
Table 3. Effectiveness of earthworm extraction from vermicompost as dependent on the bait type: cattle manure mixed with valerian or cattle manure

\begin{tabular}{|c|c|c|c|c|c|c|c|c|c|c|}
\hline \multirow{2}{*}{$\begin{array}{c}\text { Time for extraction } \\
{[\mathrm{h}]}\end{array}$} & $M+V$ & \multirow{2}{*}{$\mathrm{M}$} & $M+V$ & \multirow{2}{*}{$M$} & $M+V$ & \multirow{2}{*}{$M$} & $M+V$ & \multirow{2}{*}{$\mathrm{M}$} & $M+V$ & \multirow{2}{*}{$M$} \\
\hline & $1^{\mathrm{A}}: 20$ & & $1^{\mathrm{B}}: 20$ & & $1^{\mathrm{A}}: 10$ & & $1^{\mathrm{B}}: 10$ & & $1^{A}: 5$ & \\
\hline 24 & 28 & 12 & 16 & 12 & 16 & 28 & 15 & 14 & 8 & 11 \\
\hline 48 & 16 & 7 & 19 & 12 & 4 & 9 & 23 & 11 & 11 & 16 \\
\hline 72 & 12 & 1 & 3 & 15 & 9 & 9 & 3 & 11 & 8 & 13 \\
\hline 96 & 9 & 1 & 8 & 2 & 12 & 2 & 6 & 8 & 10 & 13 \\
\hline 120 & 5 & 2 & 7 & - & 10 & - & 2 & 7 & 5 & 2 \\
\hline 144 & 7 & - & 6 & - & 1 & - & - & - & 3 & - \\
\hline Sum & $77^{*}$ & 23 & 59 & 41 & 52 & 48 & 49 & 51 & 45 & 55 \\
\hline Total & \multicolumn{2}{|c|}{100} & \multicolumn{2}{|c|}{100} & \multicolumn{2}{|c|}{100} & \multicolumn{2}{|c|}{100} & \multicolumn{2}{|c|}{100} \\
\hline
\end{tabular}

$\mathrm{A}, \mathrm{B}$ as in table I

$\mathrm{M}+\mathrm{V}-$ cattle manure + valerian

$\mathrm{M}$ - cattle manure

* statistically significant

Table 4. Effectiveness of earthworm extraction from vermicompost as dependent on the bait type: cattle manure mixed with nettle or cattle manure

\begin{tabular}{|c|c|c|c|c|c|c|c|c|c|c|}
\hline \multirow{2}{*}{$\begin{array}{c}\text { Time for } \\
\text { extraction [h] }\end{array}$} & $M+N$ & \multirow{2}{*}{$\mathrm{M}$} & $M+N$ & \multirow{2}{*}{$M$} & $M+N$ & \multirow{2}{*}{$\mathrm{M}$} & $M+N$ & \multirow{2}{*}{ M } & $M+N$ & \multirow{2}{*}{$M$} \\
\hline & $1: 5$ & & $1: 3$ & & $2: 3$ & & $1: 1$ & & $4: 3$ & \\
\hline 24 & 9 & 13 & 18 & 12 & 12 & 11 & 13 & 15 & 15 & 18 \\
\hline 48 & 22 & 26 & 17 & 16 & 17 & 15 & 15 & 15 & 15 & 8 \\
\hline 72 & 15 & 6 & 3 & 11 & 13 & 7 & 12 & 4 & 16 & 4 \\
\hline 96 & 1 & 5 & 3 & 13 & 6 & 7 & 14 & 12 & 12 & 4 \\
\hline 120 & 1 & 2 & 3 & 4 & 3 & 6 & - & - & 3 & 3 \\
\hline 144 & - & - & - & - & - & - & - & - & 2 & - \\
\hline Sum & 48 & 52 & 44 & 56 & 51 & 49 & 54 & 46 & $63^{*}$ & 37 \\
\hline Total & \multicolumn{2}{|c|}{100} & \multicolumn{2}{|c|}{100} & \multicolumn{2}{|c|}{100} & \multicolumn{2}{|c|}{100} & \multicolumn{2}{|c|}{100} \\
\hline
\end{tabular}

$\mathrm{M}+\mathrm{N}-$ cattle manure + nettle

$\mathrm{M}$ - cattle manure

*statistically significant

Table 5. Effectiveness of earthworm extraction from vermicompost as dependent on the bait type: cattle manure mixed with flax seed or cattle manure

\begin{tabular}{|c|c|c|c|c|c|c|c|c|c|c|}
\hline \multirow{2}{*}{ Specification } & $M+F$ & \multirow{2}{*}{$M$} & $M+F$ & \multirow{2}{*}{$M$} & $M+F$ & \multirow{2}{*}{ M } & $M+F$ & \multirow{2}{*}{$M$} & $M+F$ & \multirow{2}{*}{ M } \\
\hline & $1: 3$ & & $2: 3$ & & $1: 1$ & & $4: 3$ & & $1: 0$ & \\
\hline Sum & $96^{*}$ & 4 & $92^{*}$ & 8 & $82^{*}$ & 18 & $94^{*}$ & 6 & $84^{*}$ & 16 \\
\hline Total & \multicolumn{2}{|c|}{100} & \multicolumn{2}{|c|}{100} & \multicolumn{2}{|c|}{100} & \multicolumn{2}{|c|}{100} & \multicolumn{2}{|c|}{100} \\
\hline
\end{tabular}

$\mathrm{M}+\mathrm{F}$ - cattle manure + flaxseed

$\mathrm{M}$ - cattle manure

*statistically significant

The use of nettle admixture did not change the attractiveness of the manure as a food trap (table IV). Only the mixture of nettle and manure (in 4: 3 ratio) proved significantly more attractive, although it did not cause a shortening of earthworm extraction time. Flaxseed proved very attractive (Table 5). After 6 days the majority of earthworms "rose to the bait" and were found in the flaxseed traps.

\section{DISCUSSION}

Earthworm extraction from bed using bait in a form of fresh, attractive food is a natural method without negative effects on either the population of raised earthworms or the composition of later used vermicompost.

Earthworms are characterised by particularly well developed chemotropism. The penetration 
of environment in search for food constitutes a natural process of life, a precondition for survival in the environment. Earthworm populations are characterised by a natural tendency to aggregate, and their non-uniform distribution in the substrate is the result of local availability of food they find attractive [Edwards and Bohlen 1996, Lee 1985, Depta et al. 1999].

Earthworms can be collected using a variety of means. The simplest one is to dig, but addition of a liquid e.g. formaldehyde, which acts as a skin irritant, can also be used. The food bait extraction is an ethological method, which has no negative effect on the life processes of individuals (biomass rise, breeding, or hatching of young from cocoons).

The high effectiveness of the extraction method with multiple change of bait is the evidence of the attractiveness of applied food, augmented by strong chemical stimulus causing intensive migration. Lower efficiency of single laying of bait may, on the other hand, be the effect of gradual but more intensive exhaustion of food components in the bait, and therefore lower attractiveness of the laid food due to its longer action in bait role (reducing volume, small concentration gradient), inter-population competition and the reducing concentration gradient of food ingredients.

Earthworms exhibit negative phototropism [Edwards and Bohlen 1996, Lee 1985]. Their activity in environment penetration, and therefore, their feeding intensity, is much higher at night than it is during the day. It is connected with the daily activity cycle and the depth of earthworm residence in the substrate. At night earthworms penetrate the environment more actively and in larger numbers "visit" also the surface layer. We probably get hold of such situation when we inspect the bait in the morning. During the day earthworm activity decreases and they go down, frequently even leaving the bait. Besides they may react to light and incidental vibrations, which more often appear during the day and then, when disturbed, additionally limit their activity. The grower, inspecting the bait in the morning, catches the majority of earthworms in surface layer after their all-night activity and lack of light acting onto this layer.

In other experiment [Kostecka 1999], it was determined that flaxseed is a particularly suitable food source for fast $E$. fetida reproduction and by using this food material the earthworms can easily be assembled in a single place for vermicomposting or for sale.

\section{CONCLUSIONS}

The results of the first part of the experiment are additionally confirmed by those of the second part. Since in the first test, the bait was always laid in the evening, therefore the earliest extraction of individuals from vermicompost was always attained after either 12 hours (in the morning) or 36 hours after bait laying (also in the morning). Whenever the bait was replaced after 24 hours, such a change took place again in the evening and this extended earthworm extraction from vermicompost significantly.

The experiment showed the potential of augmenting the manure attractiveness for earthworms by adding valerian (Valeriana officinalis), nettle (Urtica dioica), or flaxseed to it.

\section{REFERENCES}

1. Bouche M.B., Gardner R.H. 1984. Earthworms functions. VIII. Population estimation techniques, Rev. Ecol. Biol. Sol., 21, 37-63.

2. Depta B., Kościelniak A., Rożen A. 1999. Food selection as a mechanism of heavy metal resistance in earthworms, Pedobiologia, 43, 608-614.

3. Edwards C.A., Bohlen P.J. 1996. Biology and Ecology of Earthworms, Chapman \& Hall, London, Glasgow, Wienheim.

4. Gaddie R., Douglas D. 1977. Earthworm for ecology and profit. Bookworm Publ. Comp. Ontario, California.

5. Garg V.K., Suthar S., Yadav A. 2012. Management of food industry waste employing vermicomposting technology. Bioresource Technology. 126, 437-443.

6. Gupta R., Garg V.K. 2011. Optimization of cow dung spiked pre consumer processing vegetable waste for vermicomposting using Eisenia fetida. Ecotoxicology and Environmental Safety. 74, 19-24.

7. Gupta R., Yadav A., Garg V.K. 2014. Influence of vermicompost application in potting media on growth and flowering of marigold crop. International Journal of Recycling of Organic Waste in Agriculture. 3, 47, 1-7.

8. Kaushik P., Garg V. K. 2003. Vermicomposting of mixed textile mill sludge and cow dung with epigeic earthworm Eisenia foetida. Bioresource Technology. 90(3), 311-316.

9. Kostecka J. 1999. Usefulness of flax seeds in Eisenia fetida (Sav.) earthworm breeding, Pedobiologia 43, 776-781.

10. Kostecka J., Błażej J. 2000. Growing plants on vermicompost as a way to produce high quality foods. 
Bull. of the Polish Acad. of Scien. Biol. Scien. 48. $1,1-10$.

11. Kostecka J., Pączka G. 2006. Possible use of earthworm Eisenia fetida (Sav.) biomass for breeding aquarium fish. European Journal of Soil Biology. 42. 231-233.

12. Kostecka J. 2009. Selected aspects of the significance of earthworms in the context of sustainable waste management. In: Contemporary Problems of Management and Environmental Protection. W. Sądej (ed.) Sevages and waste materials in environment. Olsztyn. 153-170.

13. Kostecka J., Garczyńska M., Pączka G., Mroczek. J. 2011. Modelling the processes of vermicomposting in an ecological box - recognized critical points. In: Contemporary Problems of Management and Environmental Protection. No. 9. K.A. Skibniewska (ed.) Some aspects of environmental impact of waste dupms. Olsztyn. 143-156.

14. Kostecka J., Garczyńska M. 2012. Influence of chosen insecticides on the characteristics of vermicompost produced from kitchen waste. Proceedings of Ecopole, 6 (2).

15. Pączka G., Kostecka J. 2012. Trends in organic waste vermicomposting. [In:] J. Kostecka, J. Kaniuczak (Eds.) Practical Applications of Environmental Research. No. 3, Mitel, 267-281.

16. Lee K.E. 1985. Earthworms. Their ecology and relationships with soils and land use. Academic Press (Harcourt Brace Jovanovich, Publishers). Sydney. 